\title{
Preparation and Sealing Performance of a New Coal Dust Polymer Composite Sealing Material
}

\author{
Bo Li $\mathbb{D}^{1,2,3,4}$ Junxiang Zhang, ${ }^{4,5}$ Jianping Wei $\mathbb{D}^{1,2}$ and Qiang Zhang ${ }^{1,2}$ \\ ${ }^{1}$ State Key Laboratory Cultivation Base for Gas Geology and Gas Control, Jiaozuo 454000, China \\ ${ }^{2}$ The Collaborative Innovation Center of Coal Safety Production of Henan Province, Jiaozuo 454000, China \\ ${ }^{3}$ Hebei State Key Laboratory of Mine Disaster Prevention, North China Institute of Science and Technology, Beijing 101601, China \\ ${ }^{4}$ State and Local Joint Engineering Laboratory for Gas Drainage \& Ground Control of Deep Mines, Henan Polytechnic University, \\ Jiaozuo 454003, China \\ ${ }^{5}$ School of Energy Science and Engineering, Henan Polytechnic University, Jiaozuo 454003, China
}

Correspondence should be addressed to Bo Li; anquanlibo@163.com

Received 16 April 2018; Accepted 17 July 2018; Published 6 August 2018

Academic Editor: Peter Majewski

Copyright (c) 2018 Bo Li et al. This is an open access article distributed under the Creative Commons Attribution License, which permits unrestricted use, distribution, and reproduction in any medium, provided the original work is properly cited.

In this study, a new coal-dust polymer composite material (CP) was fabricated to improve the borehole gas drainage effect and address the limitations of traditional sealing materials. This material used coal dust generated during underground drilling construction as filler, amino resin as binder, and also some other additives. Based on the orthogonal test scheme, 16 groups of experiments were conducted to investigate the effects of coal-dust content, water-material ratio, and cross-linking agent content on viscosity, 3-day (3-d) compressive strength, and gel time of the CP. The influences of the various factors were studied using a range of analytical methods to obtain the optimal proportion of the CP. Moreover, the mechanical property and microstructure of the $\mathrm{CP}$ were also analyzed to evaluate the sealing performance of this material. Results showed that this material exhibited obvious plastic characteristic and could provide an effective support for the borehole; it can adapt to the deformation of the borehole to some extent and achieve a long-term sealing effect. The scanning electron microscopy (SEM) results show a good correlation between the resin molecules and coal dust inside the material, which were conducive to improve the sealing performance of the $\mathrm{CP}$ material.

\section{Introduction}

Coal bed methane (CBM) is an unconventional gas associated with coal and is largely adsorbed in coal seams and surrounding rocks. The CBM reserve in China is $3.68 \times 10^{12} \mathrm{~m}^{3}$, which ranks third in the world and is equal to the total amount of reserves of natural gas resources. Therefore, exploiting CBM is considerably significant, given that CBM is a clean and efficient energy $[1,2]$. The calorific value of $1 \mathrm{~m}^{3}$ of pure methane can reach $35.9 \mathrm{MJ}$, which is equivalent to $1.21 \mathrm{~kg}$ of standard coal, and pure methane hardly generates any exhaust gas after combustion $[3,4]$. However, CBM is also a major hazard source in coal mines. CBM pressure and content in the coal seam dramatically increase with increasing mining depth, which easily leads to a large number of gas disasters. Borehole gas drainage is the most important technical means to control gas disaster. This approach can rapidly eliminate the danger of coal and gas outburst but also can increase CBM utilization and prevent environment pollution. In 2016, the underground CBM drainage quantity in China was $1.28 \times 10^{11} \mathrm{~m}^{3}$, but the CBM utilization amounting was only $4.8 \times 10^{10} \mathrm{~m}^{3}$, with the CBM utilization rate of $37.5 \%$, which means that $8 \times 10^{10} \mathrm{~m}^{3}$ of CBM had escaped into the atmosphere. This phenomenon does not only result in a significant waste of energy but also exacerbates the greenhouse effect. The low rate of CBM utilization is mainly due to the poor sealing effect of gas drainage boreholes; approximately $65 \%$ of the coal face 
boreholes' prepumping gas concentrations in China are below $30 \%$, which completely illustrates the poor sealing quality of current boreholes $[5,6]$.

Various sealing material properties directly influence the sealing quality of boreholes. At present, sealing materials can be categorized into inorganic and organic. Inorganic sealing materials are mainly composed of cement mortar, cementwater glass, cement-fly ash, and other cement-based materials. Although these materials possess the advantages of low cost and a wide range of sources, there also exist some disadvantages, such as easy precipitation and bleeding during solidification and with volume shrinkage above $15 \%$, which tend to limit the use of the cement-based materials $[7,8]$. Beyond this amount, because of poor adhesion of the cement-based material, this material easily separates from the borehole wall, resulting in the formation of leakage channels that seriously affect the borehole gas drainage effect [9-12]. In recent years, many studies on sealing materials have been conducted. Polyurethane, as a representative of organic sealing materials, has been widely used. Due to its fast curing speed, large expansion rate, and excellent adhesion, polyurethane has achieved significant advances in sealing boreholes $[6,13,14]$. However, its fast foaming speed and high viscosity make it difficult to diffuse adequately around the borehole, which fails to achieve the ideal sealing effect; therefore, it results in a number of defects in the practical application [15-19]. Moreover, Zhou has proposed "mucus sealing" based on the idea of "solid seal liquid and liquid seal gas," but the high-pressure mucus easily leaks through the fractures around the borehole; so supplementing this mucus repeatedly is necessary, which will lead to a high cost of sealing borehole $[20,21]$. In view of the limitations of traditional sealing materials, developing a lowcost and superior-performance sealing material is necessary.

Considering the high adsorption and low permeability characteristics of coal seams in China, massive boreholes must be drilled in the coal seam to relieve CBM pressure and drain CBM to ensure underground safety during production $[22,23]$. The number of underground drilling in China has exceeded $1.5 \times 10^{8} \mathrm{~m}$ every year [24]; thereby, large amounts of coal dust from drilling constructions are discharged into the work site. The accumulated coal dust not only takes up the limited workspace and increases mine ventilation resistance but also pollutes the work environment, which significantly threatens the health of workers in the locale. If coal dust is transported to the ground, it will increase the production cost of coal mines [25-27]. In view of this, this study developed a new CP material, which used coal dust as filler and is supplemented by amino resin as binder and also some other additives. The CP can be locally obtained to reduce the cost and promote an efficient and rational utilization of coal resources; it is a new way to promote direct utilization of coal resources without burning. In this study, an orthogonal test scheme was designed, with three factors and four levels for each factor, based on the proportion conditions of the CP. The effects of coal-dust content, watermaterial ratio, and cross-linking agent content on viscosity, compressive strength, and gel time of the CP were studied to obtain the optimal proportion. Then, the sealing performance

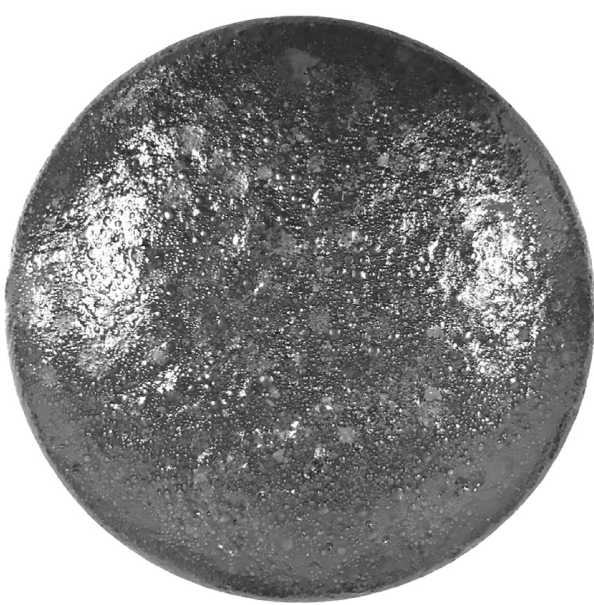

FIgURE 1: The sample of the prepared CP material.

of the CP was evaluated using mechanical analysis and SEM. The results in this study can provide a theoretical basis for the promotion and application of the CP material.

\section{Preparation of the CP}

2.1. Material Compositions. The CP material used the coal dust, which was generated from the underground drilling construction as filler, and was supplemented by amino resin as binder, and added some other additives, such as crosslinking, foaming, toughening, and coupling agents. The sample of the prepared CP material is shown in Figure 1.

Considering that the basic structural unit of the CP is composed of aromatic hydrocarbons with various condensation degrees and bridge bonds, the coal molecule has a specific rigidity, which can be added into the polymer as the rigid particles. Meanwhile, the pore structure characteristic of the coal mass and abundant groups on the margin of the coal molecule are easier to modify than other mineral fillers, which are favorable for improving the compatibility and dispersivity between the coal mass and the resin matrix [17]. On the contrary, coal dust is used as the dispersed phase to fill in the resin matrix; therefore, the size of the coal-dust particles should not be too large or too small to ensure interior integrity of the composite material. Otherwise, several internal defects or agglomeration may occur. Based on extensive researches, the size of coal dust less than $1 \mathrm{~mm}$ can meet the actual operation requirements.

The amino resin used in the material is a linear polymer, as the matrix of the composites; the resin plays the role of connecting coal particles and transferring stress. The active groups, such as carbonyl, amino, and subamino groups, on the resin molecules have strong binding characteristics that can enhance the cohesion between the coal particles and resin matrix. Moreover, the resin molecules contain many hydrophilic groups, such as ether bonds and hydroxyl groups, which can be associated with water molecules, thus forming a stable dispersion system. $-\mathrm{CH}_{2} \mathrm{OH},-\mathrm{NH}-$, and other active groups in the resin molecules allow the polycondensation reaction to form a three-dimensional network structure in the presence of a cross-linking agent. Therefore, 
the coal-dust particles can be tightly wrapped in the resin matrix with a specific mechanical intensity.

The foaming agent is a modified carbonate, which can react with hydrogen ions to produce $\mathrm{CO}_{2}$ as the expansion source that leads to volume expansion of the material. The toughening agent is a type of linear polymer compound that reacts with resin molecules under an acidic condition and embeds itself into the macromolecular chain of the resin to enhance the toughness and aging resistance of the material. The coupling agent contains a bifunctional group, which is composed of hydrolytic and nonhydrolytic groups; on the one hand, the condensation products of the hydrolytic group can react with hydroxyl $(-\mathrm{OH})$ and carboxyl $(-\mathrm{COOH})$ on the coal surface to produce a single-molecular-layer chemisorption; on the other hand, the nonhydrolytic group can result in a physical entanglement or chemical reaction with the resin molecules, which creates an interface phase between the dispersed (coal dust) and matrix (resin) phases, thereby improving the coupling process of the allogenic material.

2.2. Design of Orthogonal Test. This study utilized the orthogonal test to investigate the effect of the preparation parameters on the properties of the $\mathrm{CP}$ and to obtain the optimal proportion of the material. By conducting a number of experiments, the various contents of coal dust and watermaterial ratio that significantly influence the properties of the $\mathrm{CP}$ were examined. Meanwhile, the sealing material should possess a reasonable gel time to meet the requirements of the grouting process, which is mainly influenced by the addition amount of the cross-linking agent. Therefore, three influence factors were selected that characterize the $\mathrm{CP}$, namely, coal-dust content (A), watermaterial ratio (B), and cross-linking agent content (C). Each factor comprised four levels. In addition, the viscosity, 3-d compressive strength, and gel time of the $\mathrm{CP}$ were used as indicators in the test. A total of 16 group experiments were designed using the three factors and the four levels of the $\mathrm{L}_{16}\left(4^{5}\right)$ scheme. Tables 1 and 2 show the values of the factors and levels and the scheme of the orthogonal test.

2.3. Experimental Methods. The viscosity of the $\mathrm{CP}$ was tested using an NJD-8S rotary viscometer. The prepared grout of the $\mathrm{CP}$ was placed in a $500 \mathrm{ml}$ beaker, and then the rotor of the viscometer was immerged to a specified depth of the grout. And then the viscosity of the grout was measured at $20^{\circ} \mathrm{C}$ and $80 \%$ relative humidity.

The compressive strength of the composite materials was tested using the RMT-150B electrohydraulic servo test machine. The displacement control method was utilized in the experiments; the specimens of the $\mathrm{CP}$ were loaded with the speed of $0.02 \mathrm{~mm} / \mathrm{s}$ until damage. In the test, all samples of the CP material were curing in standard conditions for 3 days, and then the samples were processed into standard size with $\Phi 50 \mathrm{~mm} \times H \quad 100 \mathrm{~mm}$ and tested the compressive strength.

The inverted cup method was adopted to measure the gel time of the CP. We first placed the prepared grout of the $\mathrm{CP}$
TABLE 1: Values of factors and levels.

\begin{tabular}{lccc}
\hline Level & $\begin{array}{c}\text { Factor } \\
\text { Coal-dust } \\
\text { content (\%) (A) }\end{array}$ & $\begin{array}{c}\text { Water-material } \\
\text { ratio (B) }\end{array}$ & $\begin{array}{c}\text { Cross-linking agent } \\
\text { content (\%) (C) }\end{array}$ \\
\hline 1 & 50 & $1.0: 1$ & 1.5 \\
2 & 75 & $1.2: 1$ & 2.0 \\
3 & 100 & $1.5: 1$ & 2.5 \\
4 & 125 & $1.9: 1$ & 3.0 \\
\hline
\end{tabular}

TABLE 2: Scheme of the orthogonal test.

\begin{tabular}{lccc}
\hline $\begin{array}{l}\text { Test } \\
\text { group }\end{array}$ & $\begin{array}{c}\text { Coal-dust } \\
\text { content }(\%)(\mathrm{A})\end{array}$ & $\begin{array}{c}\text { Water-material } \\
\text { ratio }(\mathrm{B})\end{array}$ & $\begin{array}{r}\text { Cross-linking agent } \\
\text { content }(\%)(\mathrm{C})\end{array}$ \\
\hline 1 & $\left(\mathrm{~A}_{1}\right) 50$ & $\left(\mathrm{~B}_{1}\right) 1.0: 1$ & $\left(\mathrm{C}_{1}\right) 1.5$ \\
2 & 50 & $\left(\mathrm{~B}_{2}\right) 1.2: 1$ & $\left(\mathrm{C}_{2}\right) 2.0$ \\
3 & 50 & $\left(\mathrm{~B}_{3}\right) 1.5: 1$ & $\left(\mathrm{C}_{3}\right) 2.5$ \\
4 & 50 & $\left(\mathrm{~B}_{4}\right) 1.9: 1$ & $\left(\mathrm{C}_{4}\right) 3.0$ \\
5 & $\left(\mathrm{~A}_{2}\right) 75$ & $1.0: 1$ & 2.0 \\
6 & 75 & $1.2: 1$ & 1.5 \\
7 & 75 & $1.5: 1$ & 3.0 \\
8 & 75 & $1.9: 1$ & 2.5 \\
9 & $\left(\mathrm{~A}_{3}\right) 100$ & $1.0: 1$ & 2.5 \\
10 & 100 & $1.2: 1$ & 3.0 \\
11 & 100 & $1.5: 1$ & 1.5 \\
12 & 100 & $1.9: 1$ & 2.0 \\
13 & $\left(\mathrm{~A}_{4}\right) 125$ & $1.0: 1$ & 3.0 \\
14 & 125 & $1.2: 1$ & 2.5 \\
15 & 125 & $1.5: 1$ & 2.0 \\
16 & 125 & $1.9: 1$ & 1.5
\end{tabular}

in a $200 \mathrm{ml}$ beaker $\mathrm{A}$ and started to record time at the same time. We then poured the grout from beaker A into beaker B and repeated the above operations at every 1 minute, until the grout no longer flowed. The time of this process was the gel time.

\section{Analysis of Orthogonal Test Results}

The viscosity, 3-d compressive strength, and gel time of the 16 different group tests were tested based on the scheme of the orthogonal test; the results are listed in Table 3. According to the results, the direct analysis method was used to analyze the significance of the three factors by calculating the range value of each factor, which reflects the effect of the factor on the indicators under different levels. The order of importance of the factors can be determined on the basis of the range value, and the optimal level of each factor can be determined by combining it with the effective curves. The orthogonal test result can provide quantitative basis for the optimum proportion of the CP.

3.1. Effect of Preparation Parameters on the Viscosity of the CP. Viscosity is an important index for determining the pumpability of the sealing material. It indicates the internal friction resistance when fluid flows. A lower viscosity of the material entails better fluidity and a larger grout diffusion range in the stratum, which are conducive for sealing massive fractures around boreholes. Table 4 shows the range results of the sample viscosity as influenced by several 
TABLE 3: Experimental results of orthogonal test.

\begin{tabular}{lccc}
\hline $\begin{array}{l}\text { Test } \\
\text { group }\end{array}$ & $\begin{array}{c}\text { Viscosity } \\
(\mathrm{mPa} \cdot \mathrm{s})\end{array}$ & $\begin{array}{c}3 \text {-d } \\
\text { compressive } \\
\text { strength }(\mathrm{MPa})\end{array}$ & $\begin{array}{c}\text { Gel time } \\
(\mathrm{min})\end{array}$ \\
\hline 1 & 1035 & 4.45 & 67 \\
2 & 513 & 4.05 & 39 \\
3 & 364 & 2.82 & 19 \\
4 & 299 & 1.60 & 23 \\
5 & 1484 & 5.02 & 20 \\
6 & 774 & 4.57 & 88 \\
7 & 566 & 3.25 & 12 \\
8 & 411 & 2.35 & 38 \\
9 & 2337 & 5.98 & 9 \\
10 & 1339 & 5.17 & 7 \\
11 & 849 & 3.23 & 83 \\
12 & 569 & 2.48 & 11 \\
13 & 4150 & 4.12 & 27 \\
14 & 2769 & 4.58 & 83 \\
15 & 1988 & 3.15 & 113 \\
16 & 1299 & 2.05 & \\
\hline
\end{tabular}

TABLE 4: Range analysis of the influencing factors of viscosity.

\begin{tabular}{lccc}
\hline Level & $\begin{array}{c}\text { Coal-dust } \\
\text { content (\%) (A) }\end{array}$ & $\begin{array}{c}\text { Water-material } \\
\text { ratio (B) }\end{array}$ & $\begin{array}{c}\text { Cross-linking agent } \\
\text { content (\%) }(\mathrm{C})\end{array}$ \\
\hline 1 & 552.75 & 2251.50 & 989.25 \\
2 & 808.75 & 1348.75 & 1138.50 \\
3 & 1237.50 & 941.75 & 1470.25 \\
4 & 2551.50 & 644.50 & 1588.50 \\
Range & 1998.75 & 1607.00 & 599.25 \\
\hline
\end{tabular}

factors. The range values of the three factors, that is, coaldust content, water-material ratio, and cross-linking agent content, are 1998.75, 1607.00, and 599.25, respectively. Thus, the order of the importance of the factors to the viscosity of the $\mathrm{CP}$ is coal-dust content $>$ water-material ratio > crosslinking agent content. The results show that coal-dust content plays a significant role in controlling the viscosity.

The effective curves of the sample viscosity were constructed based on the data in Table 4, as shown in Figure 2, to analyze intuitively the effect of the various factors on viscosity. The effective curves show that the viscosity increases with the content of coal dust and cross-linking agent increasing, and decreases with the increase of the watermaterial ratio. Due to the viscosity of the material grout mainly depending on the force between the molecules in the material, as the coal-dust content increases, the friction between the coal particles will increase and lead to a sharp rise in the viscosity; as shown in Figure 2, when coal-dust content exceeds $100 \%\left(\mathrm{~A}_{3}\right)$, the viscosity increases sharply, thus the content of coal dust should not be more than $100 \%$. However, the increase in the water-material ratio can widen the distance between the particles, the friction resistance between the particles will be reduced, and the viscosity of the grout can be improved. Figure 2 shows that when the watermaterial ratio reaches 1.2:1( $\left(\mathrm{B}_{2}\right)$, the viscosity of the material grout is lower with a better fluidity. As for the cross-linking agent, it can promote the resin molecules to allow the polycondensation reaction to take place, and therefore the

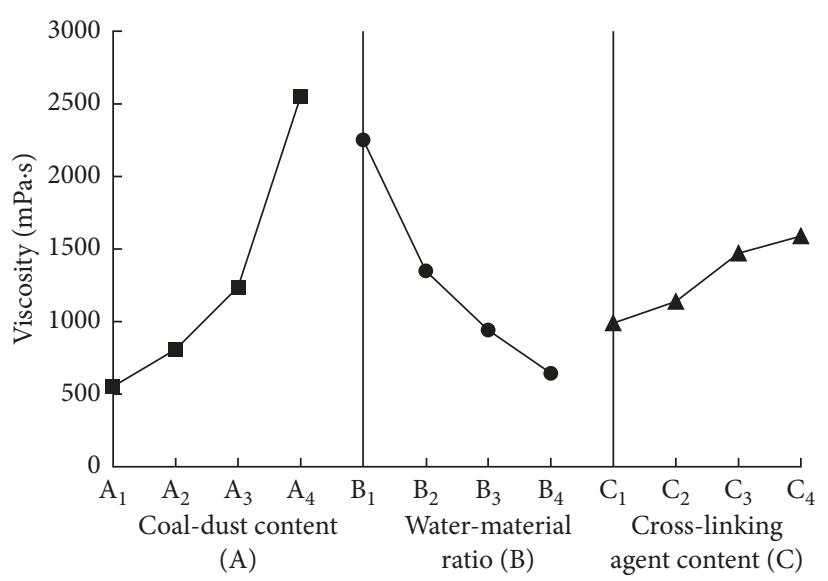

FIGURE 2: Effective curves of the factors affecting viscosity.

increase in the content of the cross-linking agent will accelerate this reaction; as a result, the prepolymer is condensed to form resin particles in the grout, and then the particles are aggregated and deposited, which result in the increase of the viscosity of the material grout. Therefore, the optimal proportion for decreasing the viscosity of the $\mathrm{CP}$ is $\mathrm{A}_{1} \mathrm{~B}_{4} \mathrm{C}_{1}$ from the orthogonal test.

3.2. Effect of Preparation Parameters on the 3-d Compressive Strength of the CP. For sealing materials, obtaining the specific early strength is necessary to achieve a timely support to the borehole and prevent the formation of leakage channels that resulted from the instability failure of the borehole. The 3-d compressive strength was used as an indicator in the orthogonal test to analyze the effect of each factor on the strength of the CP. Table 5 lists the range of the various factors from the orthogonal test results. The watermaterial ratio achieved the maximum range of 2.77 , followed by the coal-dust content of 0.99 and the cross-linking agent content of 0.40 . The results indicate that the water-material ratio is the most important factor that influences the early strength of the CP.

Figure 3 shows the effective curves of the factors that influence the 3-d compressive strength. It can be seen that the 3-d compressive strength decreases with the increase in the water-material ratio; this is because that the excess water molecules tend to attach to the surface of the coal particles, which results in the reduction of the bonding area between the resin matrix and coal particles and the internal cohesion of the material; in addition to that, during the curing of the material, when water molecules on the surface of the coal particles evaporate, it leads to the generation of a large amount of microfissures between the resin matrix and coal dust, which seriously affect the strength of the material; thus, the water-material ratio should be controlled at $1.2: 1 \sim 1.5: 1$ $\left(B_{2} \sim B_{3}\right)$ by using the above analysis of the viscosity that ensures the fluidity of the material. Meanwhile, the influence of coal-dust and cross-linking agent content on the 3-d compressive strength of the material is relatively similar. The material strength increases first and then decreases with an 
TABLE 5: Range analysis of the influencing factors of 3-d compressive strength.

\begin{tabular}{lccc}
\hline Level & $\begin{array}{c}\text { Coal-dust content } \\
(\%)(\mathrm{A})\end{array}$ & $\begin{array}{c}\text { Water-material } \\
\text { ratio (B) }\end{array}$ & $\begin{array}{c}\text { Cross-linking agent } \\
\text { content (\%) (C) }\end{array}$ \\
\hline 1 & 3.23 & 4.89 & 3.58 \\
2 & 3.80 & 4.59 & 3.68 \\
3 & 4.22 & 3.11 & 3.93 \\
4 & 3.48 & 2.12 & 3.54 \\
Range & 0.99 & 2.77 & 0.40 \\
\hline
\end{tabular}

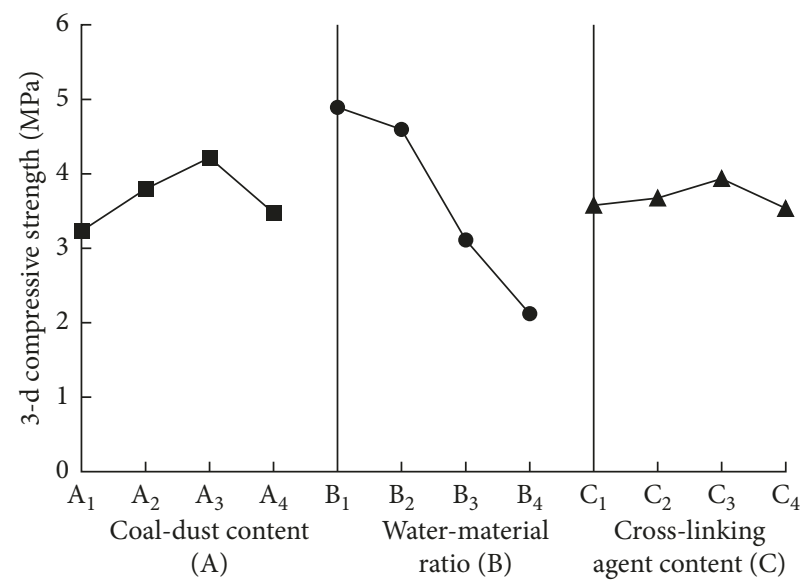

FIGURE 3: Effective curves of the factors affecting 3-d compressive strength.

increase in their content. Coal dusts form the skeleton system of the composites due to the presence of rigid particles in the resin matrix; therefore, increasing the content of coal dust in a specific range can improve the density of the material, so the compactness of the material can also be increased as the mechanical strength. By contrast, if the coal-dust content is too much, then the distance of coal particles will be decreased; therefore, the resin matrix cannot easily fill the gaps among the coal particles to transfer stress and, as a consequence, internal defects will be formed in the material that reduce the mechanical strength of the material. Figure 3 reveals that when the coal-dust content reaches $100 \%\left(\mathrm{~A}_{3}\right)$, the $\mathrm{CP}$ obtains the highest 3-d compressive strength of $4.22 \mathrm{MPa}$. For the cross-linking agent, if the content is too small, the cross-linking density of the resin matrix will be reduced. Turning the resin molecules into the stable macromolecular structure is difficult, thus resulting in the decrease in the material strength. On the contrary, if too much of the cross-linking agent is added, the cross-linking rate between the resin molecules will be too high. The resin matrix will produce a greater internal stress, thereby decreasing the mechanical strength of the CP. As shown in Figure 2, the optimal proportion for increasing the 3-d compressive strength of the $\mathrm{CP}$ is $\mathrm{A}_{3} \mathrm{~B}_{2} \mathrm{C}_{3}$.

3.3. Effect of Preparation Parameters on the Gel Time of the CP. Gel time is the controllability index of the sealing material, which directly determines the operation design of sealing technology. The appropriate gel time of the material can ensure the complete diffusion of the material gout around the borehole to achieve the ideal sealing effect. The gel time of 16 different samples are tested at a temperature of $(20 \pm 2)^{\circ} \mathrm{C}$, and the results are listed in Table 6, which show that the range value of coal-dust content, water-material ratio, and cross-linking agent content is 21.50, 37.50, and 83.50. Thus, the cross-linking agent content has a significant effect on the gel time of the material. The water-material ratio achieves an intermediate significance, whereas the coaldust content possesses a slight significance.

The effective curves of the various factors that influence the gel time are constructed based on the data in Figure 4. Figure 4 indicates that the cross-linking agent content is the most significant factor that influences the gel time. With the increase in the content of the cross-linking agent, the gel time continuously decreased with a nonlinear change trend due to the production of a specific amount of free radicals in the grout by the cross-linking agent, which can induce the occurrence of resin molecules during the polycondensation reaction. More content of the cross-linking agent will accelerate the cross-linking rate of the reaction, which results in the shortened gel time of the material. As shown in the figure, when the content is up to $2.5 \%$, it yields a favorable promotion effect. However, if the content of cross-linking agent continues to increase, the gel time is shortened, and the drop gradient is also decreased, considering that the gel time of sealing material is generally approximately 30$60 \mathrm{~min}$ in practical application. Therefore, the content of the cross-linking agent should be controlled at 2.0\% 2.5\% $\left(C_{2} \sim C_{3}\right)$. In addition, the increase in the water content in the grout can reduce the collision probability of the resin molecules. Therefore, as shown in Figure 3, the gel time increases with the increase in the water-material ratio. Meanwhile, the excess moisture can absorb the reaction temperature of the grout system, which reduces the reaction rate of the resin molecules. Furthermore, the increase in the coal-dust content can also prevent the collision of the resin molecules, which reduces the cross-linking rate and prolongs the gel time. Consequently, the optimal proportion of the appropriate gel time of the $\mathrm{CP}$ is $\mathrm{A}_{2} \mathrm{~B}_{2} \mathrm{C}_{2}$.

\subsection{Optimal Proportion of the Composite Sealing Material.} The optimal proportion for decreasing the viscosity is $A_{1} B_{4} C_{1}$, for increasing the 3-d compressive strength is $\mathrm{A}_{3} \mathrm{~B}_{2} \mathrm{C}_{3}$, and for the appropriate gel time of the $\mathrm{CP}$ is $\mathrm{A}_{2} \mathrm{~B}_{2} \mathrm{C}_{2}$, which were obtained by analyzing the experiment results of the orthogonal test. In order to acquire the optimal proportion of the CP, three types of proportion conditions were prepared for the sample materials, and the indicators were also tested. The results are shown in Table 7.

Table 7 shows that, for $\mathrm{A}_{1} \mathrm{~B}_{4} \mathrm{C}_{1}$, although this sample has the lowest viscosity, but the 3 - $d$ compressive strength is low, it cannot provide the effective support and protection for the borehole, and the grout of this sample material is easily leaked through the fractures around the borehole that resulted from the longer gel time. As for $A_{3} B_{2} C_{3}$, due to the high viscosity, its grout cannot easily penetrate into the 
TABLE 6: Range analysis of the influencing factors of gel time.

\begin{tabular}{lccc}
\hline Level & $\begin{array}{c}\text { Coal-dust } \\
\text { content (\%) (A) }\end{array}$ & $\begin{array}{c}\text { Water-material } \\
\text { ratio (B) }\end{array}$ & $\begin{array}{c}\text { Cross-linking } \\
\text { agent content (\%) (C) }\end{array}$ \\
\hline 1 & 552.75 & 2251.50 & 989.25 \\
2 & 808.75 & 1348.75 & 1138.50 \\
3 & 1237.50 & 941.75 & 1470.25 \\
4 & 2551.50 & 644.50 & 1588.50 \\
Range & 1998.75 & 1607.00 & 599.25 \\
\hline
\end{tabular}

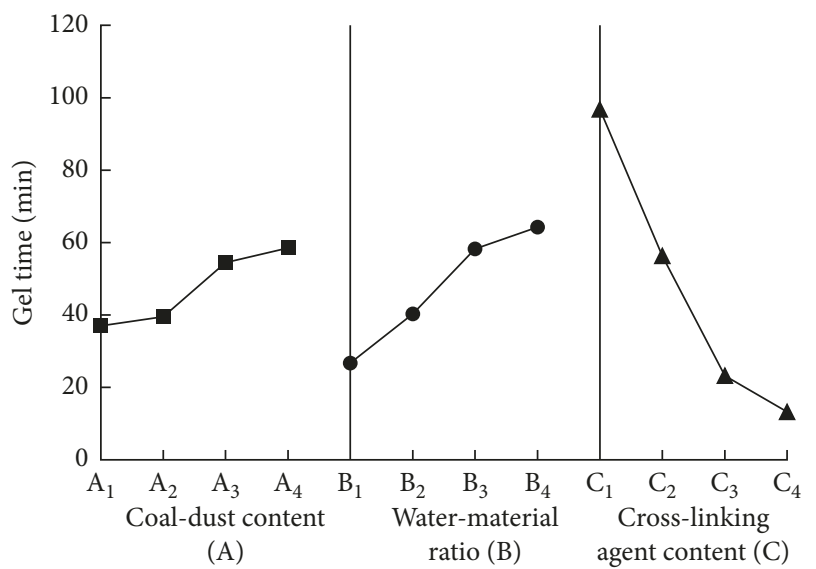

FIgURE 4: Effective curves of the factors affecting gel time.

fractures to achieve a sealing effect, so sample $A_{3} B_{2} C_{3}$ is not the ideal result. However, sample $\mathrm{A}_{2} \mathrm{~B}_{2} \mathrm{C}_{2}$ has a lower viscosity, which allows the material grout to completely diffuse around the borehole, and this sample also has a higher compressive strength and a more suitable gel time, which can achieve the technical requirements of sealing. Accordingly, the best optimal proportion of the material properties of the CP is $\mathrm{A}_{2} \mathrm{~B}_{2} \mathrm{C}_{2}$.

\section{Analysis of Sealing Performance of the CP}

4.1. Analysis of Mechanical Properties. The mechanical strength of the sealing material is a significant factor that influences the sealing effect. It does not only need a higher early strength to appropriately support the borehole timely, but it should also possess the plastic characteristic to adapt to the deformation of the borehole. In accordance with the orthogonal test results, the optimal proportion is $\mathrm{A}_{2} \mathrm{~B}_{2} \mathrm{C}_{2}$. The samples were cured at a temperature of $(20 \pm 2)^{\circ} \mathrm{C}$, with a humidity of $90 \%$. For 28 curing days, the samples were processed into the standard specimens with $\Phi 50 \mathrm{~mm} \times H$ $100 \mathrm{~mm}$, which were used to examine the mechanical properties of CP.

4.1.1. Analysis of the Stress-Strain Relation Curves of the CP. The stress-strain relation curve is an important method to examine the deformation property of the material. Figure 5 shows the results of the uniaxial compressive strength test of the three specimens.
As shown in this figure, the changing trends of the curves are basically similar. On the basis of the curves' characteristics in the chart, the failure process of the specimens comprises five stages, that is, compaction, elastic, plastic, softening, and residual strength stages. With the gradual increase of the load, all the specimens first enter the compaction stage; the stressstrain relation curves in this range are concave upside-down, then the pores and holes inside the specimen are gradually closed, which results in a slight strain change of the specimens. The specimens enter the elastic stage as the load continues to increase, the stress represents the linear relationship with the strain, and the fractures have appeared in the material in this stage. As specimens enter the plastic stage with the further increase in load, the stress varied nonlinearly with strain, which results in the deformation of the unrecoverable plastic of the material; this reveals that the fractures in the material have gradually extended and coalesced and eventually evolved into the macrocracks. When the stress on the specimens reaches the peak, the softening stage occurs, the deformation type of the specimens is transformed from compaction to expansion, and the internal structures of the material are placed along the crack surfaces; the strain of the specimens raises sharply with the development of the macrocracks; however, the mechanical strength declines. When the specimens are broken, the stress drops rapidly to a relatively stable level due to friction between the fracture planes in the material. Therefore, the specimen still experiences a specific carrying capacity.

4.1.2. Analysis of the Failure Forms of the CP. The failure form of the specimen is a significant characteristic to describe the failure mechanism of the material. Figure 6 shows the three specimens after the uniaxial compression failure. As shown in the figure, all the three specimens present a significant characteristic of plastic failure. There is a clear shear slip surface presented in each specimen. During uniaxial compression, the deformation of the specimens is axial compression and radial expansion, whereas the radial deformation in the middle part of the specimen is larger than that of both sides. This is due to the dislocation of the resin colloidal particles in the material. When the radial strain value of the specimen exceeds the ultimate tensile strain, the cracks are gradually generated on the surface of the material and gradually extended to the interior, until the specimen is damaged.

The mechanical properties of the $\mathrm{CP}$ indicate that this material possesses a typical plastic characteristic, and it can provide effective supports for the borehole and can adapt to the borehole deformation to some extent. Thus, it can avoid the instant damage caused by the stress changes, which is conducive to improve the stability of the borehole to achieve a long-term drainage effect.

4.2. Microstructure Analysis of the CP. The microstructure of the CP was observed using a JSM-6390/LV SEM, which can magnify 5-300000 times with resolution of $3.0 \mathrm{~nm}$ and an acceleration voltage of $0.5-30 \mathrm{kV}$. Figure 7 shows the SEM images of the $\mathrm{CP}$ at 300 times magnification. 
TABLe 7: Experimental results of the three kinds of materials.

\begin{tabular}{lccc}
\hline $\begin{array}{l}\text { Test } \\
\text { group }\end{array}$ & $\begin{array}{c}\text { Viscosity } \\
(\mathrm{mPa} \cdot \mathrm{s})\end{array}$ & $\begin{array}{c}\text { 3-d compressive } \\
\text { strength }(\mathrm{MPa})\end{array}$ & $\begin{array}{c}\text { Gel time } \\
(\mathrm{min})\end{array}$ \\
\hline $\mathrm{A}_{1} \mathrm{~B}_{4} \mathrm{C}_{1}$ & 234 & 1.32 & 86 \\
$\mathrm{~A}_{3} \mathrm{~B}_{2} \mathrm{C}_{3}$ & 1201 & 5.33 & 23 \\
$\mathrm{~A}_{2} \mathrm{~B}_{2} \mathrm{C}_{2}$ & 781 & 4.71 & 47 \\
\hline
\end{tabular}

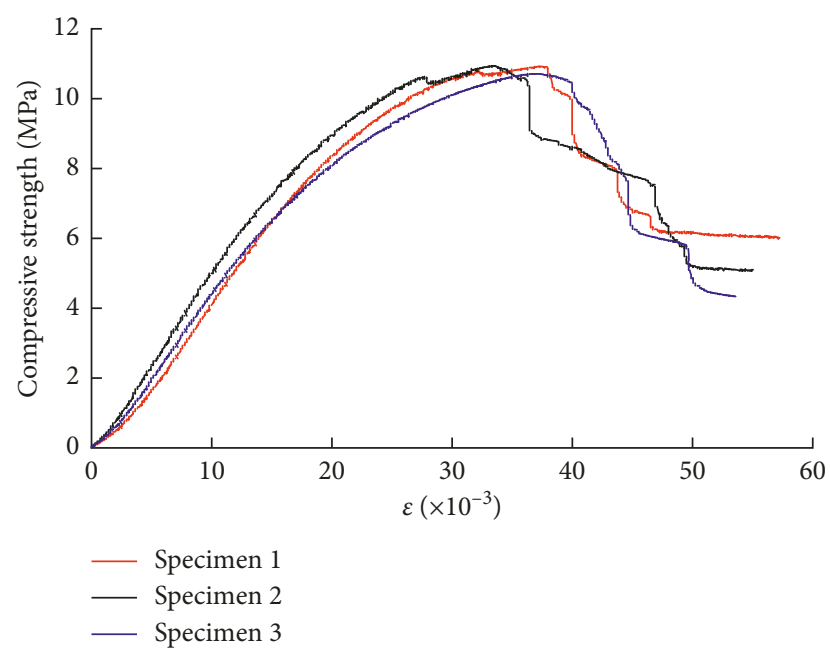

FIGURE 5: Stress-strain relation curves of the specimens.

Figure 7(a) shows that the structure of the $\mathrm{CP}$ is dense and that several isolated pores are distributed in the material, which are produced by a foaming agent to promote the volume expansion of the material. It can be seen that the coal-dust particles are dispersed uniformly in the material and closely embedded in the resin matrix, which form the carrier of the composites, thereby improving the mechanical strength of the material.

Figure 7(b) shows the scanning result of the resin matrix at 2500 times magnification. This figure clearly shows that a great number of colloidal particles are distributed in the resin matrix. The matrix skeleton and internal pores are intersected and intertwined into a dense network structure due to the unique structure of the resin. When the CP is in the loading process, the resin matrix first yields and produces plastic deformation. Then, the colloidal particles are dislocated to allow the deformation of the material until failure. Therefore, the plastic capacity characteristic of the resin plays a significant role in transferring stress and dissipating energy to the composite materials. However, a modulus difference exists between coal mass and resin matrix. The interfaces are relatively weaker than the surfaces of the $\mathrm{CP}$, which easily yield stress concentration under load. Therefore, the binding ability between them directly influences the overall performance of the material.

Figure 7(c) shows the result of the interface structure of the CP. This figure shows a better combination effect on the interface. No obvious gaps are found between the coal particle and the resin matrix. In addition, the adhesion layer of the resin can be observed on the surface of the coal particles due to a large number of active groups present in

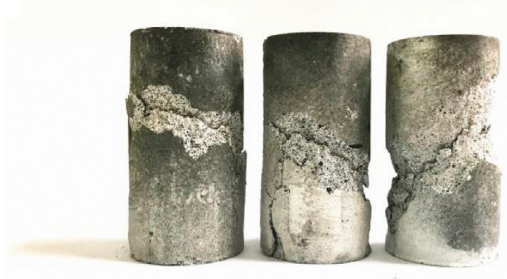

Figure 6: The failure type of the specimen.

the resin molecule, such as the carbonyl group $(-\mathrm{C}=\mathrm{O}-)$, amino group $\left(-\mathrm{NH}_{2}\right)$, and imino group (-NH-). These groups have a fine adhesion attached on the surface of the coal dust through physical reaction or chemical grafting to form a unified unit. Therefore, the silicon-oxygen (Si-O) and magnesium-oxygen ( $\mathrm{Mg}-\mathrm{O})$ bonds in the coal molecules can create an association with the hydrogen atoms of the hydroxymethyl $\left(-\mathrm{CH}_{2} \mathrm{OH}\right)$ in the resin, which improves the stability of the interface between the coal dust and resin matrix.

\section{Discussion of Sealing Performance of the CP}

The results show that the CP has a superior sealing performance that can satisfy the technical requirements for sealing boreholes. As shown in Figure 8, the sealing mechanisms of $\mathrm{CP}$ can be generalized as follows.

5.1. Preferable Fluidity. The optimal proportion of the $\mathrm{CP}$ is $\mathrm{A}_{2} \mathrm{~B}_{2} \mathrm{C}_{2}$, with a low viscosity of $781 \mathrm{MPa} \cdot \mathrm{s}$, using the orthogonal test. This material can meet the technical requirements of low-pressure grouting and can completely diffuse in the coal seam. The solid-phase particles of the coal dust in the material can fill the holes and macrofractures. The liquid-phase of the resin matrix can seal the microfractures around the borehole. This combination can further improve the sealing effect of the drainage borehole.

5.2. Adapt to the Deformation of Borehole. In the CP, coal dust is used as filler, and amino is chosen as binder. The coal dust continuously distributed in the material forms the skeleton system of the CP. The resin matrix disperses and transfers stress. The $\mathrm{CP}$, with the characteristic of plastic strengthening, can adapt to the deformation of boreholes that resulted from the stress change in the surrounding rocks, which ensures the stability of gas drainage borehole as well as a long-term drainage effect.

5.3. Stable Combination with Coal Mass. SEM results show a good correlation between the resin molecules and coal dust; the resin matrix plays a role of transferring stress, and the coal dust forms the carrier to bear external stress changes. Accordingly, combination of them improves the sealing effect and achieves a superior drainage effect. 


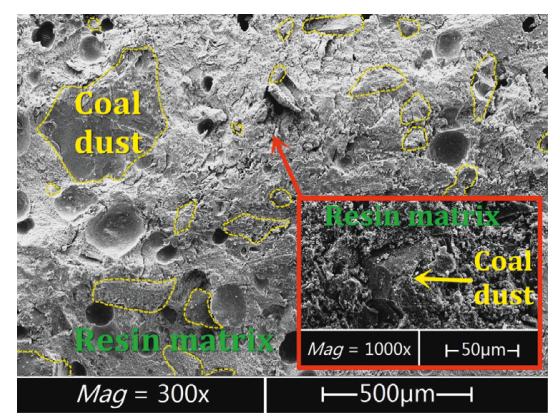

(a)

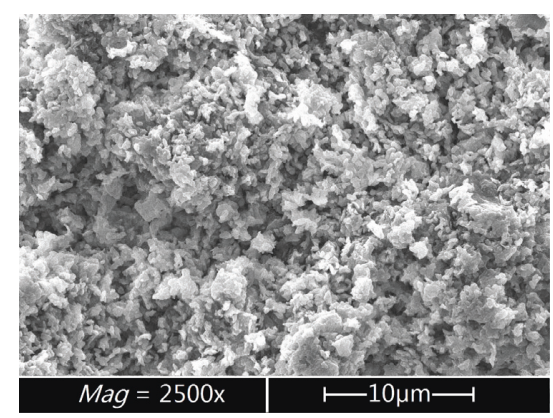

(b)

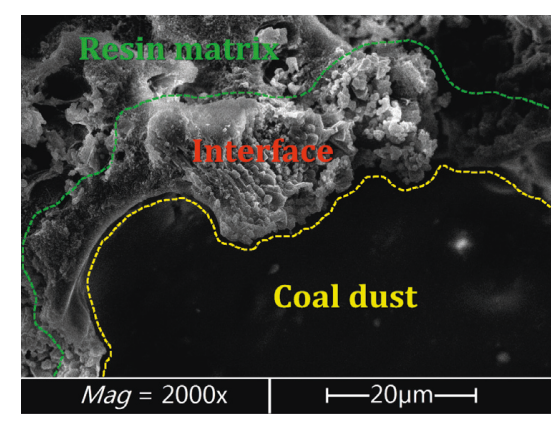

(c)

Figure 7: Microstructure of the composite material. (a) The CP material, (b) resin matrix, and (c) interface structure.

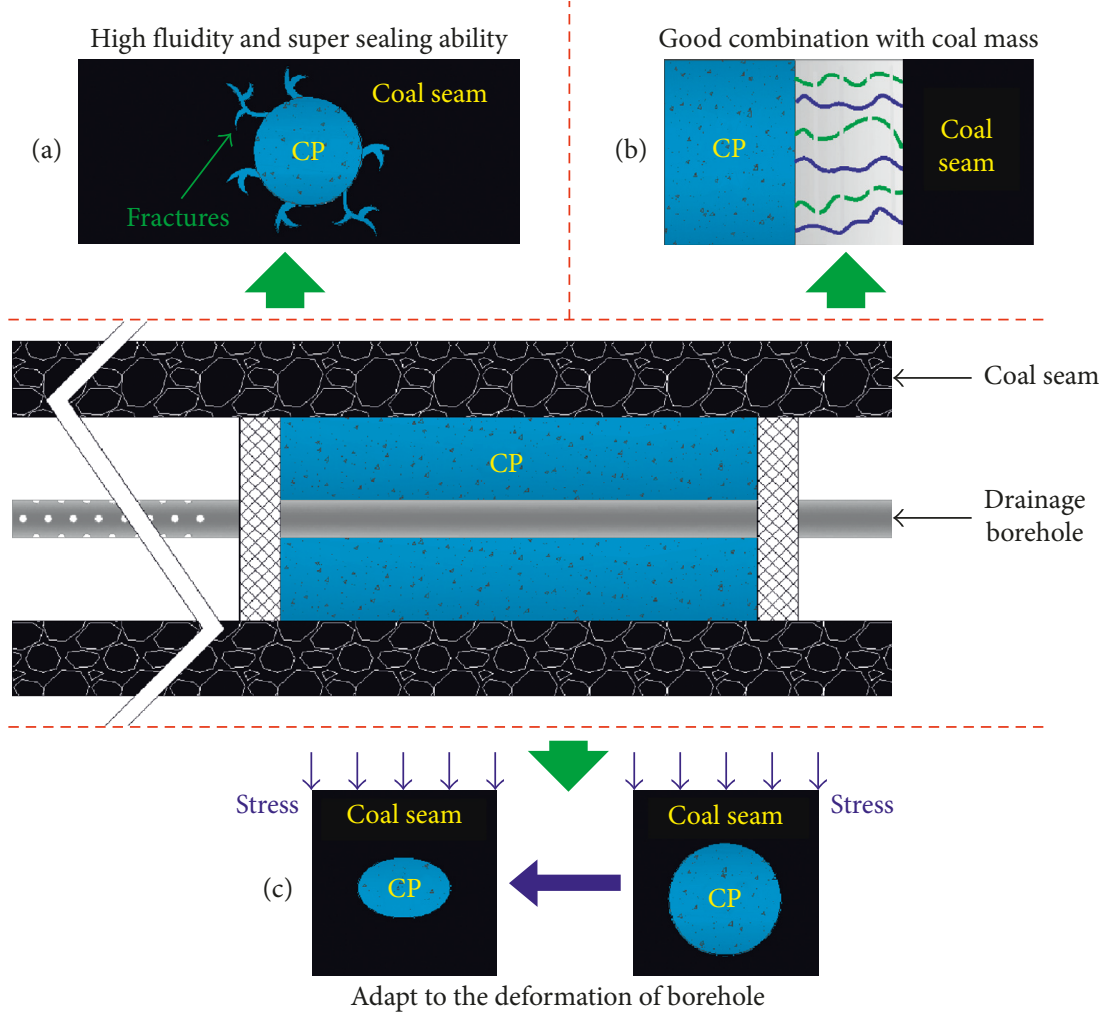

FIGURE 8: Sealing performance of CP material.

\section{Conclusions}

(1) An orthogonal test scheme of 16 groups of experiments was designed to determine the optimal coaldust content, water-material ratio, and cross-linking agent and the four levels used for each factor as well as the effects of viscosity, 3-d compressive strength, and gel time on the properties of the CP.

(2) The range analysis of the results of orthogonal test showed that the significant factors that influence the viscosity followed the order coal-dust content $>$ watermaterial ratio $>$ cross-linking agent content. The order of importance of the three factors based on their influence on the 3 -d compressive strength is water- material ratio $>$ coal-dust content $>$ cross-linking agent content. The rank of importance in terms of gel time is cross-linking agent content $>$ water-material ratio $>$ coal-dust content. The optimal proportion of the $\mathrm{CP}$ is found to be $\mathrm{A}_{2} \mathrm{~B}_{2} \mathrm{C}_{2}$ by comparing and analyzing the selected materials.

(3) Mechanical property test showed that the CP possessed a high compressive strength with a significant plastic characteristic. Thus, the $\mathrm{CP}$ can provide the support to boreholes and adapt to deformation to a certain extent. And SEM results reveal that a good correlation between the resin molecules and coal dust. In general, these results demonstrated that the $\mathrm{CP}$ has a superior sealing performance. 


\section{Data Availability}

The data used to support the findings of this study are available from the corresponding author upon request.

\section{Conflicts of Interest}

The authors declare that they have no conflicts of interest.

\section{Acknowledgments}

This study was supported by Program for National Natural Science Foundation of China (nos. 51774120 and 51604096), Hebei State Key Laboratory of Mine Disaster Prevention (KJZH2017K08), and Henan Research Program of Application Foundation and Advanced Technology (162300410031) and funded by the Research Fund of State and Local Joint Engineering Laboratory for Gas Drainage \& Ground Control of Deep Mines (Henan Polytechnic University) (G201609), Key Research Project of Higher Education Institution of Henan Province in 2015 (no. 15A440001), and Dr. Funds of Henan Polytechnic University (no. B2015-05).

\section{References}

[1] M. Qingmin, Z. Zhonglin, and P. Fangwei, "Development trends of natural gas resources and gas-fired power generations in China," Environmental Progress and Sustainable Energy, vol. 35, no. 3, pp. 853-858, 2016.

[2] C. Peng, C. Zou, T. Zhou et al., "Factors affecting coalbed methane (CBM) well productivity in the Shizhuangnan block of southern Qinshui basin, North China: investigation by geophysical log, experiment and production data," Fuel, vol. 191, pp. 427-441, 2017.

[3] G. J. Millar, S. J. Couperthwaite, and C. D. Moodliar, "Strategies for the management and treatment of coal seam gas associated water," Renewable and Sustainable Energy Reviews, vol. 57, pp. 669-691, 2016.

[4] Y. P. Cheng, J. Dong, W. Li, M. Y. Chen, and K. Liu, "Effect of negative pressure on coalbed methane extraction and application in the utilization of methane resource," Journal of the China Coal Society, vol. 42, no. 6, pp. 1466-1474, 2017.

[5] C. Zhai, X. Xiang, Q. Zou, X. Yu, and Y. Xu, "Influence factors analysis of a flexible gel sealing material for coal-bed methane drainage boreholes," Environmental Earth Sciences, vol. 75, p. 385, 2016.

[6] N. G. Hua, L. B. Quan, Z. Cheng et al., "Microscopic properties of drilling sealing materials and their influence on the sealing performance of boreholes," Journal of University of Science and Technology Beijing, vol. 35, no. 5, pp. 572-579, 2013.

[7] H. Samouh, E. Rozière, and A. Loukili, "Influence of formwork duration on the shrinkage, microstructure, and durability of cement-based materials," Nature, vol. 185, no. 4711, pp. 439-441, 2015.

[8] P. Chaunsali and P. Mondal, "Influence of mineral admixtures on early-age behavior of calcium sulfoaluminate cement," ACI Materials Journal, vol. 112, no. 1, pp. 1-6, 2015.

[9] X. Chen, Y. Zhang, W. Sun, X. Ge, and R. Zhao, "Research on expansion property of inorganic hole sealing material of coal mine," Materials Research Innovations, vol. 19, no. 8, pp. S8142-S8-144, 2015.

[10] M. I. Childers, M. T. Nguyen, K. A. Rod et al., "Polymercement composites with self-healing ability for geothermal and fossil energy applications," Chemistry of Materials, vol. 29, no. 11, pp. 4708-4718, 2017.

[11] S. W. Lee, G. T. Chae, M. Jo, and T. Kim, "Comparison of portland cement (KS and API class G) on cement carbonation for carbon storage," Journal of Materials in Civil Engineering, vol. 27, no. 1, article 04014105, 2015.

[12] Z. Cheng, Y. Xu, N. Guanhua, L. Min, and H. Zhiyong, "Microscopic properties and sealing performance of new gas drainage drilling sealing material," International Journal of Mining Science and Technology, vol. 23, no. 4, pp. 475-480, 2013.

[13] Y. Jiang, T. C. Zhu, and T. X. Wang, "Research and application of pressure measurement technology by combination sealing of capsule and polyurethane," Journal of Safety Science and Technology, vol. 35, no. 5, pp. 80-84, 2015.

[14] Z. Q. Feng and H. P. Kang, "Technology research of chemical grouting for cracked coalrock mass and demonstration project," Journal of Yangtze River Scientific Research Institute, vol. 26, no. 7, pp. 60-65, 2013.

[15] Y. Wei, A. M. Asce, F. Wang, X. Gao, and Y. Zhong, "Microstructure and fatigue performance of polyurethane grout materials under compression," Journal of Materials in Civil Engineering, vol. 29, no. 9, article 04017101, 2017.

[16] P. K. R. Vennapusa, Y. Zhang, and D. J. White, "Comparison of pavement slab stabilization using cementitious grout and injected polyurethane foam," Journal of Performance of Constructed Facilities, vol. 30, no. 6, article 04016056, 2016.

[17] M. Genedy, U. F. Kandil, E. N. Matteo, J. Stormont, and M. M. R. Taha, "A new polymer nanocomposite repair material for restoring wellbore seal integrity," International Journal of Greenhouse Gas Control, vol. 58, pp. 290-298, 2017.

[18] J. Scucka, P. Martinec, and K. Soucek, "Polyurethane grouted gravel type geomaterials-a model study on relations between material structure and physical-mechanical properties," Geotechnical Testing Journal, vol. 38, no. 2, article 20140100, 2015.

[19] H. Liu, W. Hui, C. Zhuang, Y. Liu, and Y. Jian, "Preparation of EA/PU IPN grouting material and its performances research," Journal of Central South University, vol. 44, no. 8, pp. 31293136, 2013.

[20] Z. Cheng, X. W. Xiang, Y. U. Xu, P. Shen, N. I. Guan-Hua, and L. I. Min, "Sealing performance of flexible gel sealing material of gas drainage borehole," Journal of China University of Mining and Technology, vol. 42, no. 6, pp. 982-988, 2013.

[21] F. B. Zhou, Y. N. Sun, H. J. Li, and G. F. Yu, "Research on the theoretical model and engineering technology of the coal seam gas drainage hole sealing," Journal of China University of Mining and Technology, vol. 45, no. 3, pp. 433-439, 2016.

[22] T. Xia, F. Zhou, J. Liu, and F. Gao, "Evaluation of the predrained coal seam gas quality," Fuel, vol. 130, no. 130, pp. 296-305, 2014.

[23] Y. S. Kang, L. Z. Sun, B. Zhang, J. Y. Gu, and D. L. Mao, "Discussion on classification of coalbed reservoir permeability in china," Journal of the China Coal Society, vol. 42, pp. 186-194, 2017.

[24] Y. L. Wang, W. B. Song, Y. N. Sun, X. X. Zhai, and Z. F. Wang, "Clogging mechanical model and its application in gas 
extraction borehole," Journal of Chongqing University, vol. 37, no. 9, pp. 119-127, 2014.

[25] Y. Chen, L. Y. Wang, and S. Q. Zhu, "Surface modification effects of microorganism from lignite on fine coal," Advanced Materials Research, vol. 868, no. 9, pp. 423-428, 2013.

[26] J. Lu, S. Jiang, J. Tao, and J. Hu, "Analysis of dust to evaluate the incidence of pneumoconiosis in Huainan coal mines," Analytical Letters, vol. 49, no. 11, pp. 1783-1793, 2016.

[27] Q. Huang and R. Honaker, "Optimized reagent dosage effect on rock dust to enhance rock dust dispersion and explosion mitigation in underground coal mines," Powder Technology, vol. 301, pp. 1193-1200, 2016. 


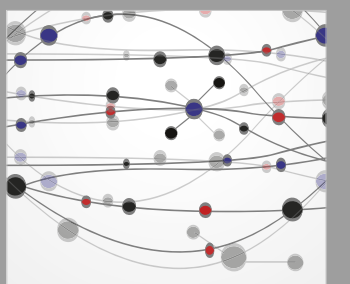

The Scientific World Journal
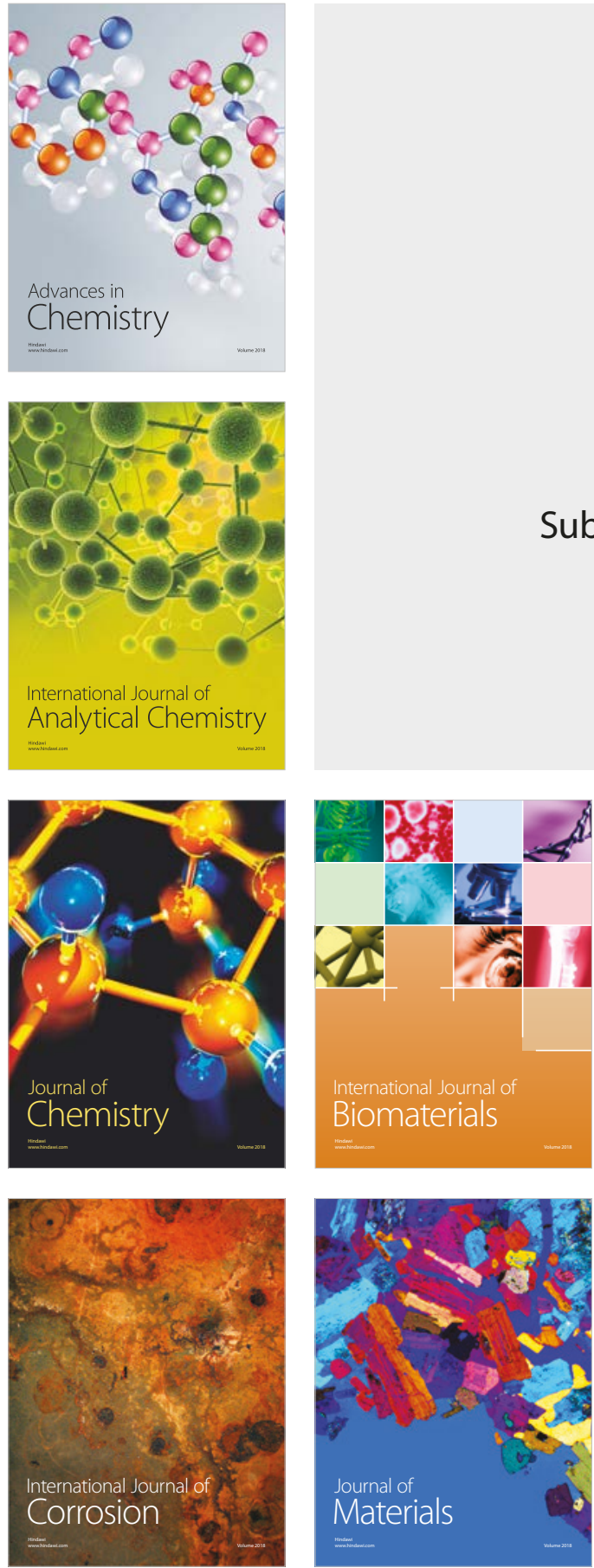

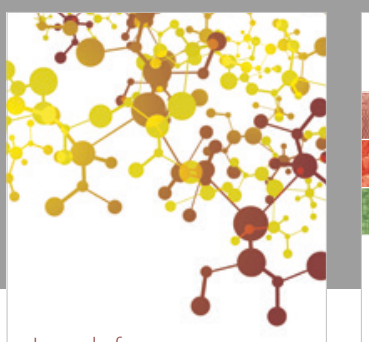

Journal of

Applied Chemistry
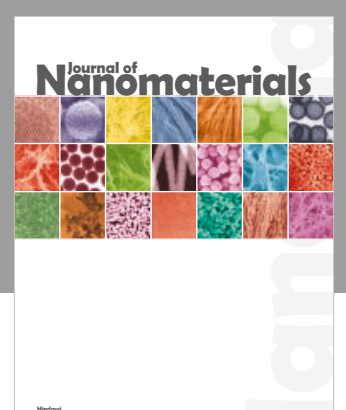

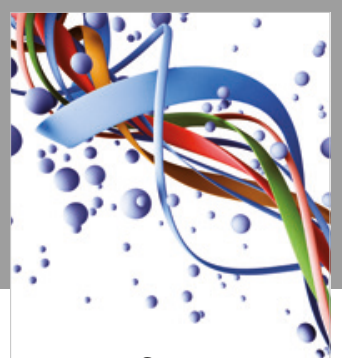

Scientifica

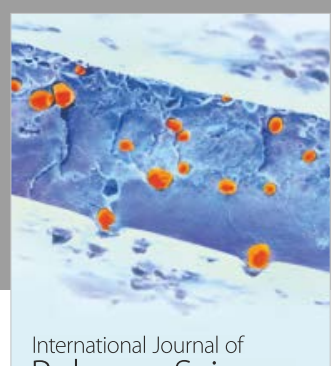

Polymer Science

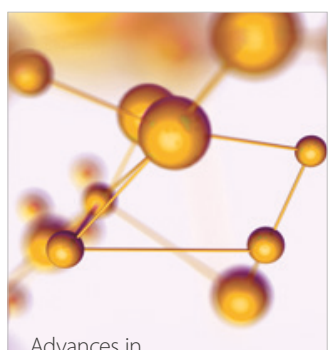

Physical Chemistry
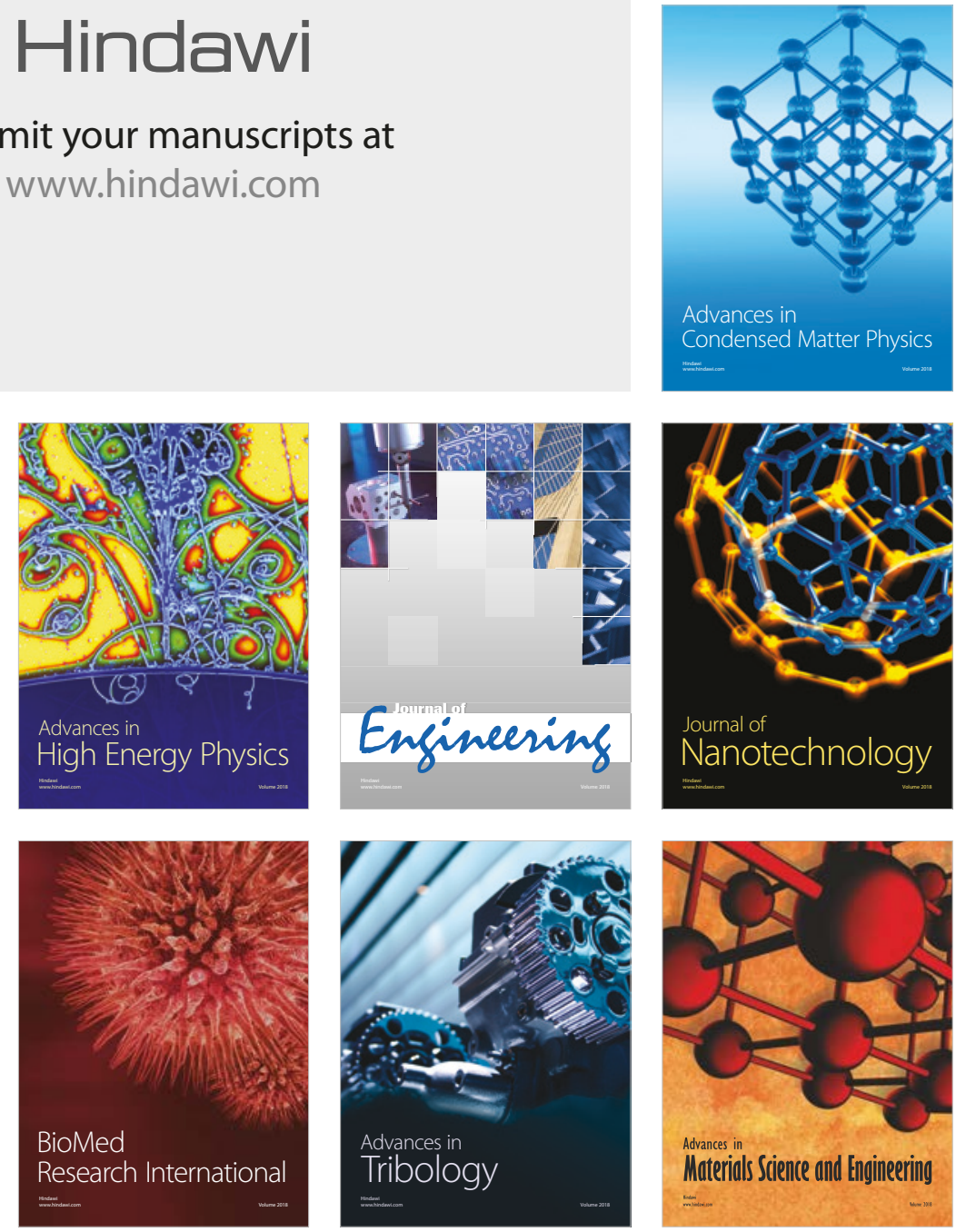